\title{
Marginal reticular cells: a stromal subset directly descended from the lymphoid tissue organizer
}

\section{Tomoya Katakai*}

Department of Molecular Genetics, Institute of Biomedical Science, Kansai Medical University, Moriguchi, Osaka, Japan

\section{Edited by:}

Christopher G. Mueller, Centre

National de la Recherche Scientifique,

France

Reviewed by:

Scott Mueller, The University of

Melbourne, Australia

Tom Cupedo, Erasmus University

Medical Center, Netherlands

\section{*Correspondence:}

Tomoya Katakai, Department of Molecular Genetics, Institute of Biomedical Science, Kansai Medical University, 10-15 Fumizono-cho, Moriguchi, Osaka 570-8506, Japan. e-mail:katakait@takii.kmu.ac.jp
The architecture of secondary lymphoid organs (SLOs) is supported by several nonhematopoietic stromal cells. Currently it is established that two distinct stromal subsets, follicular dendritic cells and fibroblastic reticular cells, play crucial roles in the formation of tissue compartments within SLOs, i.e., the follicle and T zone, respectively. Although stromal cells in the anlagen are essential for SLO development, the relationship between these primordial cells and the subsets in adulthood remains poorly understood. In addition, the roles of stromal cells in the entry of antigens into the compartments through some tissue structures peculiar to SLOs remain unclear. A recently identified stromal subset, marginal reticular cells (MRCs), covers the margin of SLOs that are primarily located in the outer edge of follicles and construct a unique reticulum. MRCs are closely associated with specialized endothelial or epithelial structures for antigen transport. The similarities in marker expression profiles and successive localization during development suggest that MRCs directly descend from organizer stromal cells in the anlagen. Therefore, MRCs are thought to be a crucial stromal component for the organization and function of SLOs.

Keywords: CXCL13, fibroblastic reticular cell, follicular dendritic cell, lymph node, marginal reticular cell, organizer, secondary lymphoid organ, stromal cell

\section{INTRODUCTION}

Secondary lymphoid organs/tissues (SLOs) are essential for the efficient induction of adaptive immune responses. Several types of SLOs, including the lymph nodes (LNs), spleen, and mucosalassociated lymphoid tissues (MALTs) such as Peyer's patches (PPs), are strategically positioned throughout various places within the body. SLOs are an elaborate filter that samples antigens and is equipped with highly sensitive immune sensors. In order to collect and filtrate foreign antigens, SLOs contain specialized tissue structures that are associated with the endothelium or epithelium. Immune cells such as lymphocytes, dendritic cells (DCs), and macrophages accumulate to high densities and form compartments. A remarkable feature common to all SLOs is the segregated localization of $\mathrm{B}$ cells and $\mathrm{T}$ cells. The architecture of SLOs is supported by several types of non-hematopoietic stromal cells of mesenchymal origin, which construct networks and define compartments (Mueller and Germain, 2009; Roozendaal and Mebius, 2011). Stromal networks provide not only a functional foothold but also a space for immune cell activities, as well as a physical framework for the tissue. Moreover, growing evidence indicates that stromal cells also play critical roles in immune cell function and homeostasis (Link et al., 2007; Fletcher et al., 2010;

Abbreviations: DC, dendritic cell; FAE, follicle-associated epithelium; FDC, follicular dendritic cell; FRC, fibroblastic reticular cell; HEV, high endothelial venue; IFC, interfollicular channel; IFR, interfollicular region; LN, lymph node; LT, lymphotoxin; LTi, lymphoid tissue inducer; LTo, lymphoid tissue organizer; MALT, mucosal associated lymphoid tissue; MRC, marginal reticular cell; MS, marginal sinus; MZ, marginal zone; PALS, periarteriolar lymphoid sheath; PP, Peyer's patch; SED, subepithelial dome; SLO, secondary lymphoid organ; SCS, subcapsular sinus; TLT, tertiary lymphoid tissue.
Suzuki et al., 2010; Lukacs-Kornek etal., 2011). SLOs are programmed to develop from the anlagen that occur at certain places and during restricted periods in the fetus and infant. In addition, stromal cells are known to be important for SLO development and maintenance (Mebius, 2003). Here, I focus on a recently identified stromal subset, marginal reticular cells (MRCs), and summarize their characteristics. I also discuss the relationship between MRCs and tissue structure, other stromal subsets, and immunological functions.

\section{T AND B CELL COMPARTMENTS AND TWO CONVENTIONAL STROMAL CELL SUBSETS}

As described above, $\mathrm{B}$ cells and $\mathrm{T}$ cells localize to distinct regions within SLOs. B cells accumulate to form follicles (B zone) in the outer cortex beneath the capsule in LNs or in the outer periarteriolar lymphoid sheath (PALS) in the spleen. A cluster of large follicles is the core tissue of PPs. During immune responses, activated B cells in the follicles form germinal centers, where they differentiate into high-affinity antibody producers (Cyster et al., 2000). In contrast, $T$ cells localize to a separate area ( $\mathrm{T}$ zone) adjacent to the follicles, i.e., the paracortex in LNs, inner PALS in the spleen, or interfollicular region (IFR) in PPs. DCs also accumulate in the $\mathrm{T}$ zone to present antigen and prime $\mathrm{T}$ cells (Steinman et al., 1997).

There are two different types of mesenchymal stromal subsets in the $\mathrm{B}$ and $\mathrm{T}$ zones (Figure 1A). Follicular dendritic cells (FDCs) form a dense network in the center of the follicles and have received considerable attention because of their importance in antibody production by B cells (Tew et al., 1997; 


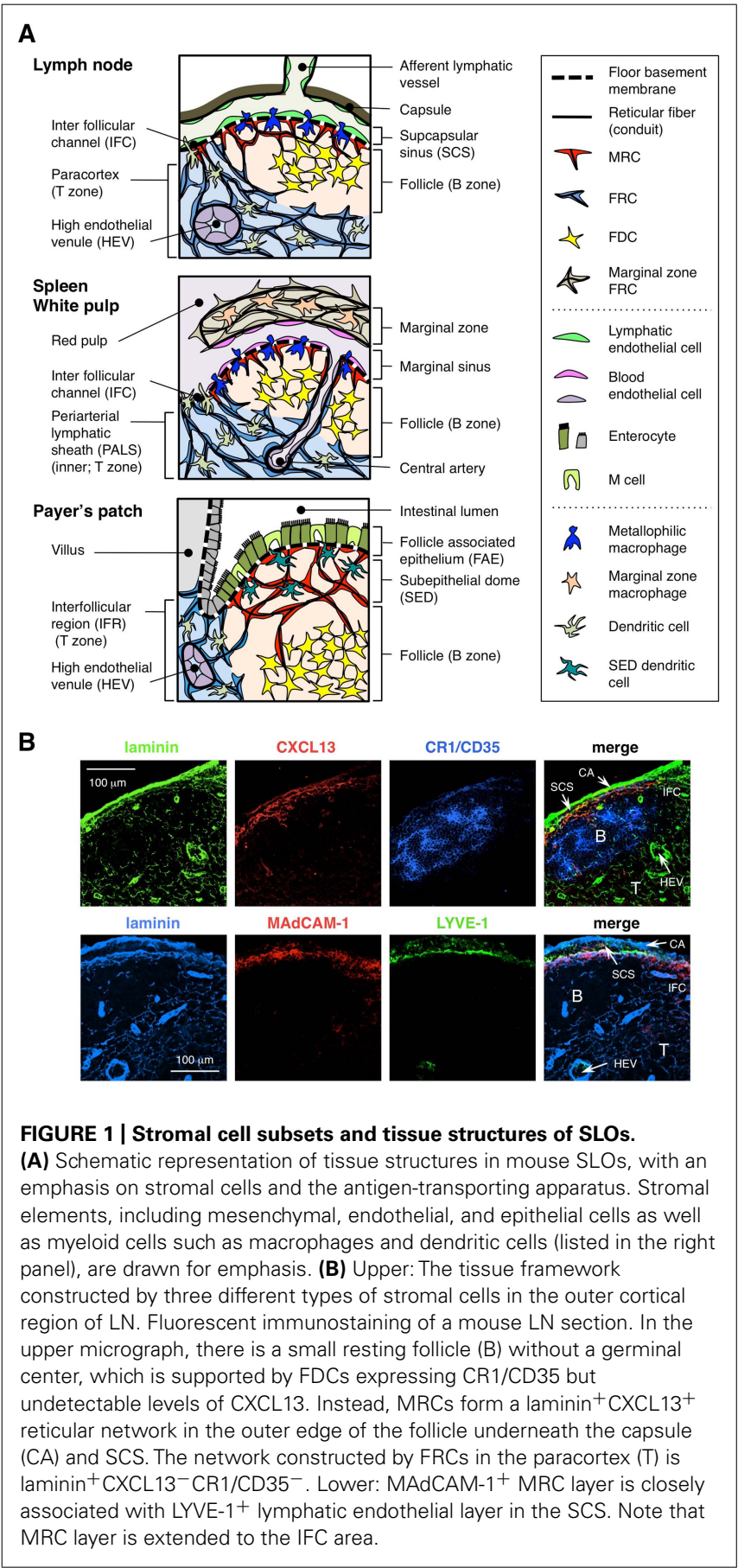

Cyster et al., 2000; Victoratos etal., 2006; Suzuki et al., 2010). FDCs express CR1/CD35, CD23, and occasionally MAdCAM-1 (Szabo et al., 1997; Cyster et al., 2000). By contrast, an elaborate network of fibroblastic reticular cells (FRCs) comprises the scaffold of the T zone, which produces podoplanin/gp38 and various extracellular matrix (ECM) components (Gretz et al., 1997; Luther et al., 2000; Kaldjian et al., 2001; Katakai et al., 2004a,b). In general, immune cell migration and localization are regulated by a variety of chemokines (Mackay, 2001). Resting lymphocytes and mature DCs are highly responsive to "homeostatic chemokines"
(Cyster, 1999; Müller etal., 2003). Consistent with this, there are clear correlations between chemokines produced by stromal cell subsets and the localization of immune cells expressing the corresponding receptors; CXCL13 produced by FDCs is an attractant of B cells expressing CXCR5, while CCL19 and CCL21 from $\mathrm{T}$ zone FRCs attract $\mathrm{T}$ cells and mature DCs through the common receptor CCR7 (Cyster, 1999; Cyster et al., 2000; Luther et al., 2000). Moreover, lymphocytes that migrate robustly in the tissue parenchyma to scan antigens are thought to use stromal networks as a foothold (Bajénoff et al., 2006). A variety of factors produced by stromal subsets are also required for the activation and survival of immune cells (Cyster et al., 2000; Huber et al., 2005; Link et al., 2007; Suzuki et al., 2010; Lukacs-Kornek et al., 2011; Malhotra et al., 2012). Therefore, the structure and function of the stromal network in each compartment is likely optimized for the activity of immune cell subsets.

The stromal network in the T zone is composed of FRCs and an ECM bundle known as a reticular fiber, which forms a "conduit" that facilitates the passage of low molecular weight substances (Gretz et al., 1997, 2000; Nolte et al., 2003). This conduit transports various factors and soluble antigens deep within the tissue, while particles and large molecules are predominantly excluded from the lymphocyte compartments. Indeed, lymph-borne chemokines from peripheral tissues are rapidly transported to the high endothelial venule through the conduit to control the mobilization of circulating cells into the LNs (Palframan et al., 2001). In addition, some resident DCs directly contact the conduit and capture lymph-borne antigens (Sixt et al., 2005).

\section{A NEWLY IDENTIFIED STROMAL SUBSET, MARGINAL RETICULAR CELLS}

The outer margin of the LN cortex, just beneath capsule, is surrounded by the subcapsular sinus (SCS; Figure 1A). The luminal surface of the SCS is covered with lymphatic endothelial cells and their cortical side is backed by the basement membrane, called the "floor" (Szakal et al., 1983). Particularly within the IFRs, reticular fibers spread out from the floor into the paracortex (Gretz et al., 1997). Importantly, a thin layer of reticular structure is also observed in the outermost region of the follicles. FRC-like stromal cells in the follicular reticulum express CXCL13 and MAdCAM-1 but not CCL21, which indicates that these cells are distinct from $\mathrm{T}$ zone FRCs, while the FDC marker CR1/CD35 was undetected or only weakly expressed in these cells (Katakai et al., 2008; Figures 1B and 2A). FDCs do not generate reticular fibers, and accordingly, the reticular marker ER-TR7 is virtually absent in the center of the follicles (Katakai et al., 2004a,b). In addition, reticular cells in the subcapsular region specifically express RANKL/TRANCE, which is a TNF family cytokine that is essential for LN development (Dougall et al., 1999; Kong et al., 1999). Therefore, these stromal cells were thought to be a new stromal subset and were designated marginal reticular cells (MRCs; Katakai et al., 2008). Of note, a substantial amount of CXCL13 is constitutively expressed in MRCs in resting small follicles even if FDCs express undetectable levels of CXCL13 (Figure 1B). It is well established that the outer edge of PALS in the spleen, especially that which lies over the follicles, is bordered by a MAdCAM- $1^{+}$ 


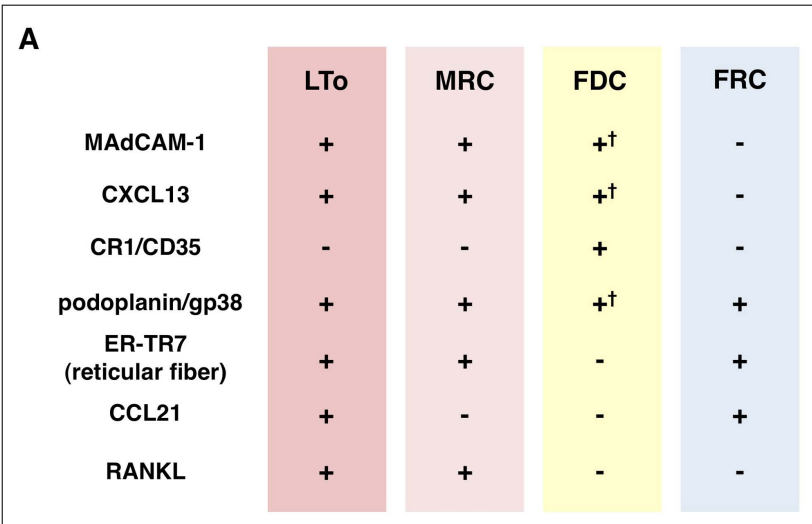

B

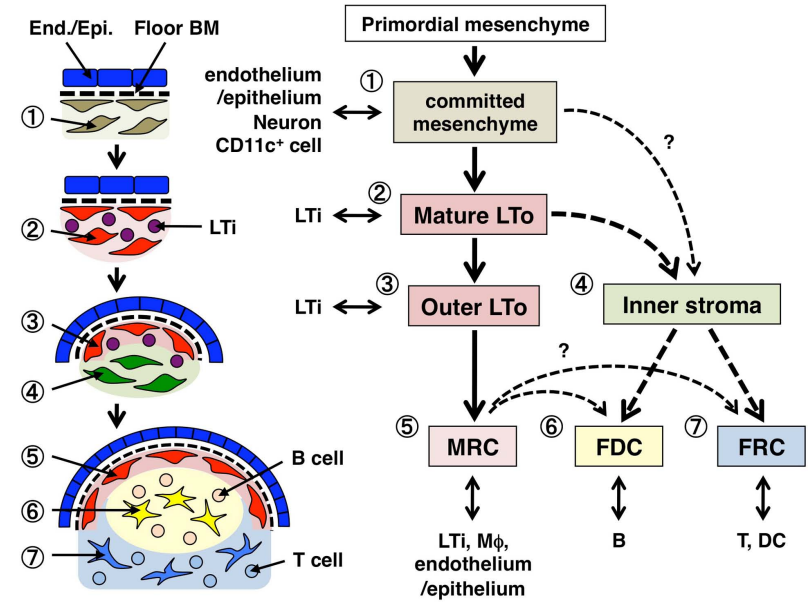

FIGURE 2 | Relationship between MRCs and other stromal cell subsets in SLOs. (A) Pattern of marker expression in stromal cell subsets. Expression levels of MAdCAM-1, CXCL13, and podoplanin/gp38 in FDCs are often weak or undetectable by immunohistochemistry ( $($ ). (B) Schematic of a generalized model of SLO development with the locations of stromal cell subsets (left) and a putative genealogy of stromal cell subsets (right). Numbers indicating cell elements in the left drawing represent stromal cell subsets shown in the right scheme. BM, basement membrane; End./Epi., endothelial or epithelial layer.

stromal layer. The cells that constitute the lining of basement membrane beneath the marginal sinus (MS) also express CXCL13 and RANKL, indicating that these cells are a type of MRCs (Katakai et al., 2008). In MALTs, reticular cells similar to MRCs form a network in the subepithelial dome (SED) region just under the basement membrane of the follicle-associated epithelium (FAE; Katakai et al., 2008; Knoop et al., 2009). Taken together, MRCs are thought to be a stromal subset common to SLOs but distinct from FDCs and FRCs.

\section{MRCS AND THE ANTIGEN ENTRY ROUTE IN SLOs}

Secondary lymphoid organs are characterized by peculiar structures that filtrate and transport antigens into the lymphocyte compartments (Figure 1A). LNs are connected with lymphatic vessels to survey lymph-borne antigens. Because the afferent lymphatics are open to the SCS, the sinus lymphatic endothelium and floor basement membrane are, as it were, the front surface of the LN filter. The spleen filters blood, in which branches of the central artery open to the MS and marginal zone (MZ), where immune cells survey the blood contents. In these specialized sinus structures, the border barriers are the lymphatic endothelium in the SCS of the LN and the blood endothelium in the MS of the spleen, both of which are supported by the MRC reticulum. Interestingly, $\mathrm{CD} 169^{+}$metallophilic macrophages are selectively distributed near the sinus lining over the follicles, some of which settle across the endothelial barrier and convey particulate antigens from the sinus lumen into the lymphocyte compartment (Szakal et al., 1983; Taylor et al., 2005; Carrasco and Batista, 2007; Phan et al., 2009). DCs that carry antigens from the tissues via the lymphatic vessels arrive at the SCS and subsequently move into the paracortex across the floor of the interfollicular channel (IFC; Steinman et al., 1997; Katakai et al., 2004b; Braun et al., 2011). In MALTs, the FAE functions as the barrier in which a specialized epithelial cell called M cells transfers bacteria or particles from the gut lumen to underlying DCs or macrophages (Kraehenbuhl and Neutra, 2000). Therefore, MRCs support the frontline antigentransporting apparatus in each SLO. The basic design of SLOs is that the follicles are primarily arranged toward the site of antigen entry and are accompanied by $\mathrm{T}$ zones. Thus, from a stromal viewpoint, the whole tissue architecture appears to be organized toward the MRC layer.

Although the immunological functions of MRCs remain elusive, it was previously shown that the conduit network constructed by MRCs in the outer follicle transports small soluble antigens to follicular B cells and FDCs (Bajénoff and Germain, 2009; Roozendaal et al., 2009). Most $\mathrm{CD} 169^{+}$macrophages are positioned at the cortical side of the SCS floor and protrude an extension into the sinus lumen to capture particles (Phan et al., 2009). Thus, MRCs might be involved in the localization, morphology, and function of these macrophages. $\mathrm{M}$ cell development in PPs requires RANKL-RANK signaling, which is likely controlled by a RANKL-expressing MRC network just beneath the FAE (Knoop et al., 2009). Inhibiting the LT pathway, which abolishes MRC signatures in the splenic white pulp, disturbs the MS structure (Koike etal., 1996; Balogh et al., 2007; Katakai et al., 2008; Zindl et al., 2009). Moreover, elevated ICAM-1, VCAM-1, and CXCL13 expression implies that MRCs are involved in the dynamic interstitial migration of follicular B cells as a functional scaffold. $\mathrm{CD} 169^{+}$macrophages have been shown to directly deliver particulate antigens to antigen-specific B cells in this area (Carrasco and Batista, 2007; Phan et al., 2009), suggesting that MRC network-mediated control of B cell migration may impact this process. Since MRCs are also present in the IFC region, they possibly regulate the transmigration of DCs from the SCS toward the $\mathrm{T}$ zone.

\section{MRCS AND ORGANIZER STROMAL CELLS IN SLO DEVELOPMENT}

Secondary lymphoid organs develop from the anlagen, which are aggregates of mesenchymal and hematopoietic cells associated with vessels or epithelium, at a defined site and period in the fetus or infant (Mebius, 2003). A critical event in the development of the SLO anlagen is the accumulation of $\mathrm{CD} 45^{+} \mathrm{CD} 4^{+} \mathrm{CD}^{-}$ hematopoietic cells, which are also known as lymphoid tissue 
inducer (LTi) cells that interact with mesenchymal stromal cells called lymphoid tissue organizer (LTo) cells (Mebius et al., 1997). A TNF family cytokine, lymphotoxin (LT)- $\alpha 1 \beta 2$ that is expressed by LTi cells transmits signals to LTo cells via the LT- $\beta$ receptor. LTo cells subsequently induce the expression of adhesion molecules, including ICAM-1, VCAM-1, and MAdCAM-1, and chemokines CXCL13, CCL19, and CCL21 (Honda et al., 2001; Cupedo et al., 2004a; Bénézech et al., 2010). In particular, CXCL13 is especially important in attracting LTi cells to the anlagen via its receptor CXCR5 (Finke et al., 2002; Luther et al., 2003; Ohl et al., 2003). It is assumed that a positive feedback loop, i.e. newly immigrating LTi cells that produce LT further activate LTo stromal cells, promoting the organization of the anlagen. As lymphocytes began to accumulate after birth, the tissue expands and the compartments supported by different stromal cell subsets are induced (Cupedo et al., 2004b; Bajénoff and Germain, 2009).

Marginal reticular cells and LTo cells express a very similar pattern of various markers (Figure 2A), suggesting that there is some relationship between these two stromal cells. LTo cells seem to be more concentrated in the marginal region of the LN anlagen adjacent to the lymphatic sinus of the presumptive SCS (Finke et al., 2002; Cupedo et al., 2004a; Eberl et al., 2004; Katakai et al., 2008). This LTo cell layer appears to expand outwardly with the growth of the anlagen, which ultimately appears to become the MRC layer (Katakai et al., 2008). Likewise, as lymphocytes accumulate around the central artery in the postnatal spleen, LTo cells expressing MAdCAM-1 and RANKL expand with the layer and become MRCs in the white pulp. These findings strongly suggest that MRCs are a direct descendant of the LTo stroma, which preserve the characteristics of LTo cells at specialized sites within SLOs. Even RAG-deficient mice exhibit a subcapsular MRC layer in atrophic LNs and shrunken periarterial MRC sheathes in the spleen, indicating that MRC development occurs independently of $\mathrm{B}$ and $\mathrm{T}$ cells and is programmed before their colonization (Katakai etal., 2008). Since SLOs efficiently sample antigens to trigger immune responses, the antigen-collecting structures that are constructed during development need to be maintained thereafter. Accordingly, it is reasonable that these tissue structures are maintained by organizer-like stromal cells throughout adulthood.

\section{RELATIONSHIP BETWEEN MRCS AND OTHER STROMAL SUBSETS}

Figure 2B shows the possible genealogy of stromal subsets in SLOs. In the embryo, the primordial mesenchyme that is in close proximity to the vasculature or epithelium is committed to form the anlage core and attracts LTi cells. Nerve cells or other less characterized cells are also involved in the initial process (Veiga-Fernandes et al., 2007; van de Pavert et al., 2009). The accumulation of LTi cells facilitates the maturation of mesenchymal cells into LTo cells, which ultimately facilitates the construction of the basic architecture. Typically, LTo cells tend to concentrate at the periphery of the anlage and expand outward with tissue growth, while stromal cells exhibiting weak or no LTo signatures conversely increase in the inner portion of the anlage. Postnatal colonization of B and $\mathrm{T}$ cells leads to compartments with the induction of conventional stromal subsets.
If this scheme is correct, it follows that all the stromal subsets in adult SLOs are originally derived from LTo cells. Thus, do MRCs that preserve the characteristics of LTo cells have the ability to differentiate into FDCs or FRCs? MRCs share many signatures with other subsets (Figure 2A), suggesting that this is possible. One speculation is that MRCs function as stromal stem cells that continuously supply all of the stromal subsets throughout adulthood. Although this idea is intriguing, it will require cautious consideration and further validation in the future. Mesenchymal cells are generally highly flexible in nature depending on the surrounding environment, and thus specific features can be easily changed. Extended culturing of stromal cells isolated from LNs results in lost expression for many genes, particularly homeostatic chemokines (Katakai et al., 2004a; Tomei et al., 2009). This suggests that the in vivo phenotypes of stromal cell subsets are optimally maintained by the tissue circumstances, which are reversible and not due to terminal differentiation. In addition, inflammatory stimuli induce the robust proliferation of stromal cells and the dramatic remodeling of SLOs (Katakai et al., 2004a; Chyou et al., 2011). Therefore, although MRCs could be converted to other subsets, conventional stromal subsets might also self-renew and be interchangeable in adult SLOs.

\section{REMODELING OF SLOS AND TERTIARY LYMPHOID STRUCTURES}

During immune responses, stromal structures within SLOs are dramatically remodeled (Gretz et al., 1997; Katakai et al., 2004a). Some infections cause a severe disruption of tissue structures within the LNs and splenic white pulp within a few days, which is restored as the pathogens are eradicated (Mueller et al., 2007a,b; Scandella et al., 2008; St John and Abraham, 2009). This restoration process likely recapitulates a self-organizing process via a feedback reaction similar to SLO development. Importantly, LTi-like cells are also present in adult tissues and regulate infectionassociated remodeling of SLOs (Kim et al., 2003; Scandella et al., 2008). Although the role of MRCs in such processes is unknown, they possibly have an organization role in collaboration with LTi-like cells and determine the outer frame of SLOs during reconstruction.

In chronic inflammation associated with various organ pathologies, large numbers of infiltrating lymphocytes often lead to organizations that are similar to SLOs, known as tertiary lymphoid tissues (TLTs; Drayton etal., 2006). B and T cells are segregated and corresponding networks of stromal cell subsets are induced. It would be interesting to determine whether MRCs are present in these ectopic lymphoid structures; however, MRC-like cells and related tissue structures are not observed in TLTs that developed during mouse autoimmune gastritis (Katakai et al., 2006, 2008). It should be emphasized that TLTs are fundamentally not programmed lymphoid organizations and naturally do not associate with the antigen-transporting structures. Therefore, MRCs are likely absent in TLTs. Even though stromal cells that are phenotypically similar to MRCs might be induced in some lesions, they would not be identified as MRCs unless they closely associate with the specific endothelial or epithelial structure and form a layered reticulum at the outer follicles. 


\section{CONCLUSION}

Marginal reticular cells are a unique stromal cell subset common to SLOs. MRCs are clearly different from conventional subsets that are induced or maturated through interactions with lymphocytes after birth, and are directly derived from LTo stromal cells in the anlagen and independent of lymphocytes. The network of MRCs is closely associated with the antigen-transporting apparatus of SLOs and is thought to directly or indirectly control antigen delivery to lymphocyte compartments as well as the localization and migration of immune cells. MRCs likely play pivotal roles in maintaining SLO structures as the outer framework

\section{REFERENCES}

Bajénoff, M., Egen, J. G., Koo, L. Y., Laugier, J. P., Brau, F., Glaichenhaus, N., and Germain, R. N. (2006). Stromal cell networks regulate lymphocyte entry, migration, and territoriality in lymph nodes. Immunity 25, 989-1001.

Bajénoff, M., and Germain, R. N. (2009). B-cell follicle development remodels the conduit system and allows soluble antigen delivery to follicular dendritic cells. Blood 114, 4989-4997.

Balogh, P., Balázs, M., Czömpöly, T., Weih, D. S., Arnold, H. H., and Weih, F. (2007). Distinct roles of lymphotoxin-beta signaling and the homeodomain transcription factor $\mathrm{Nkx} 2.3$ in the ontogeny of endothelial compartments in spleen. Cell Tissue Res. 328, 473-486.

Bénézech, C., White, A., Mader, E., Serre, K., Parnell, S., Pfeffer, K., Ware, C. F., Anderson, G., and Caamaño, J. H. (2010). Ontogeny of stromal organizer cells during lymph node development. J. Immunol. 184, 4521-4530.

Braun, A., Worbs, T., Moschovakis, G. L., Halle, S., Hoffmann, K., Bölter, J., Münk, A., and Förster, R. (2011). Afferent lymph-derived $\mathrm{T}$ cells and DCs use different chemokine receptor CCR7-dependent routes for entry into the lymph node and intranodal migration. Nat. Immunol. 12, 879-887.

Carrasco, Y. R., and Batista, F. D. (2007). $B$ cells acquire particulate antigen in a macrophage-rich area at the boundary between the follicle and the subcapsular sinus of the lymph node. Immunity 27, 160-171.

Chyou, S., Benahmed, F., Chen, J., Kumar, V., Tian, S., Lipp, M., and Lu, T. T. (2011). Coordinated regulation of lymph node vascular-stromal growth first by CD11c+ cells and then by $\mathrm{T}$ and $\mathrm{B}$ cells. J. Immunol. 187, 5558-5567.

Cupedo, T., Vondenhoff, M. F., Heeregrave, E. J., De Weerd, A. E., Jansen, W., Jackson, D. G., Kraal, G., and
Mebius, R. E. (2004a). Presumptive lymph node organizers are differentially represented in developing mesenteric and peripheral nodes. $J$. Immunol. 173, 2968-2975.

Cupedo, T., Lund, F. E., Ngo, V. N., Randall, T. D., Jansen, W., Greuter, M. J., de Waal-Malefyt, R., Kraal, G., Cyster, J. G., and Mebius, R. E. (2004b). lymph nodes is regulated by non-B cell-derived signals and is not dependent on CXC chemokine ligand 13. J. Immunol. 173, 4889-4896.

Cyster, J. G. (1999). Chemokines and organs. Science 286, 2098-2102.

Cyster, J. G., Ansel, K. M., Reif, K., Ekland, E. H., Hyman, P. L., Tang, H. L., Luther, S. A., and Ngo, V. N. (2000). Follicular stromal cells and lymphocyte homing to follicles. Immunol. Rev. 176: 181-193.

Dougall, W. C., Glaccum, M., Charrier, K., Rohrbach, K., Brasel, K., De Smedt, T., Daro, E., Smith, J., Tometsko, M. E., Maliszewski, C. R., Armstrong, A., Shen, V., Bain, S., Cosman, D., Anderson, D., Morrissey, P. J., Peschon, J. J., and Schuh, J. (1999). RANK is essential for osteoclast and lymph node development. Genes Dev. 13, 2412-2424.

Drayton, D. L., Liao, S., Mounzer, R. H., and Ruddle, N. H. (2006). Lymphoid organ development: from ontogeny to neogenesis. Nat. Immunol. 7, 344-353.

Eberl, G., Marmon, S., Sunshine, M. J., Rennert, P. D., Choi, Y., and Littman, D. R. (2004). An essential function for the nuclear receptor $\operatorname{ROR} \gamma(\mathrm{t})$ in the generation of fetal lymphoid tissue inducer cells. Nat. Immunol. 5, 64-73.

Finke, D., Acha-Orbea, H., Mattis, A., Lipp, M., and Kraehenbuhl, J. (2002). CD4+CD3 - cells induce Peyer's patch development: role of $\alpha 4 \beta 1$ integrin activation by CXCR5. Immunity 17, 363-373.

Fletcher, A. L., Lukacs-Kornek, V., Reynoso, E. D., Pinner, S. E., Initiation of cellular organization in cell migration in secondary lymphoid

and may be converted to other stromal subsets at steady state or during tissue remodeling. It will be important to collectively consider all the stromal subsets, tissue structures, and immunological microenvironments in order to comprehensively understand the SLO system.

\section{ACKNOWLEDGMENTS}

This work was supported in part by Grant-in-Aid for Young Scientist and for Scientific Research on Innovative Areas from The Ministry of Education, Culture, Sports, Science, and Technology of Japan.

Bellemare-Pelletier, A., Curry, M. S., Collier, A. R., Boyd, R. L., and Turley, S. J. (2010). Lymph node fibroblastic reticular cells directly present peripheral tissue antigen under steady-state and inflammatory conditions. J. Exp. Med. 207, 689-697.

Gretz, J. E., Anderson, A. O., and Shaw, S. (1997). Cords, channels, corridors and conduits: critical architectural elements facilitating cell interactions in the lymph node cortex. Immunol. Rev. 156, 11-24.

Gretz, J. E., Norbury, C. C., Anderson, A. O., Proudfoot, A. E., and Shaw, S. (2000). Lymph-borne chemokines and other low molecular weight molecules reach high endothelial venules via specialized conduits while a functional barrier limits access to the lymphocyte microenvironments in lymph node cortex. J. Exp. Med. 192, 1425-1440.

Honda, K., Nakano, H., Yoshida, H., Nishikawa, S., Rennert, P., Ikuta, K., Tamechika, M., Yamaguchi, K., Fukumoto, T., Chiba, T., and Nishikawa, S.-I. (2001). Molecular basis for hematopoietic/mesenchymal interaction during initiation of Peyer's patch organogenesis. J. Exp. Med. 193, 621-630.

Huber, C., Thielen, C., Seeger, H. Schwarz, P., Montrasio, F., Wilson, M. R., Heinen, E., Fu, Y. X., Miele, G., and Aguzzi, A. (2005). Lymphotoxin- $\beta$ receptor-dependent genes in lymph node and follicular dendritic cell transcriptomes. J. Immunol. 174, 5526-5536.

Kaldjian, E. P., Gretz, J. E., Anderson, A. O., Shi, Y., and Shaw, S. (2001). Spatial and molecular organization of lymph node $\mathrm{T}$ cell cortex: a labyrinthine cavity bounded by an epithelium-like monolayer of fibroblastic reticular cells anchored to basement membrane-like extracellular matrix. Int. Immunol. 13, 1243-1253.

Katakai, T., Hara, T., Sugai, M., Gonda, H., and Shimizu, A. (2004a). Lymph node fibroblastic reticular cells construct the stromal reticulum via contact with lymphocytes. J. Exp. Med. 200, 783-795.

Katakai, T., Hara, T., Lee, J. H., Gonda, H., Sugai, M., and Shimizu, A. (2004b). A novel reticular stromal structure in lymph node cortex: an immuno-platform for interactions among dendritic cells, $\mathrm{T}$ cells and $\mathrm{B}$ cells. Int. Immunol. 16, 1133-1142.

Katakai, T., Nomura, T., Gonda, H., Sugai, M., Agata, Y., Nishio, A., Masuda, T., Sakaguchi, S., and Shimizu, A. (2006). Spontaneous large-scale lymphoid neogenesis and balanced autoimmunity versus tolerance in the stomach of $\mathrm{H}+/ \mathrm{K}+-\mathrm{ATPase}$-reactive TCR transgenic mouse. J. Immunol. 177, 78587867.

Katakai, T., Suto, H., Sugai, M., Gonda, H., Togawa, A., Suematsu, S., Ebisuno, Y., Katagiri, K., Kinashi, T., and Shimizu, A. (2008). Organizerlike reticular stromal cell layer common to adult secondary lymphoid organs. J. Immunol. 181, 6189-6200.

Kim, M. Y., Gaspal, F. M., Wiggett, H. E., McConnell, F. M., Gulbranson-Judge, A., Raykundalia, C., Walker, L. S. Goodall, M. D., and Lane, P. J. (2003). CD4+ CD3 - accessory cells costimulate primed CD4 $\mathrm{T}$ cells through OX40 and CD30 at sites where T cells collaborate with B cells. Immunity 18 , 643-654.

Knoop, K. A., Kumar, N., Butler, B. R., Sakthivel, S. K., Taylor, R. T., Nochi, T., Akiba, H., Yagita, H., Kiyono, H., and Williams, I. R. (2009). RANKL is necessary and sufficient to initiate development of antigen-sampling $M$ cells in the intestinal epithelium. $J$. Immunol. 183, 5738-5747.

Koike, R., Nishimura, T., Yasumizu, R., Tanaka, H., Hataba, Y., Hataba, Y., Watanabe, T., Miyawaki, S., and Miyasaka, M. (1996). The splenic marginal zone is absent in alymphoplastic aly mutant mice. Eur. J. Immunol. 26, 669-675.

Kong, Y. Y., Yoshida, H., Sarosi, I., Tan, H. L., Timms, E., Capparelli, C., Morony, S., Oliveira-dos-Santos, A. J., Van, G., Itie, A., Khoo, W., 
Wakeham, A., Dunstan, C. R., Lacey, D. L., Mak, T. W., Boyle, W. J., and Penninger, J. M. (1999). OPGL is a key regulator of osteoclastogenesis, lymphocyte development and lymph-node organogenesis. Nature 397, 315-323.

Kraehenbuhl, J. P., and Neutra, M. R. (2000). Epithelial M cells: differentiation and function. Annu. Rev. Cell Dev. Biol. 16, 301-332.

Link, A., Vogt, T. K., Favre, S., Britschgi, M. R., Acha-Orbea, H., Hinz, B., Cyster, J. G., and Luther, S. A. (2007). Fibroblastic reticular cells in lymph nodes regulate the homeostasis of naive T cells. Nat. Immunol. 8, 1255-1265.

Lukacs-Kornek, V., Malhotra, D., Fletcher, A. L., Acton, S. E., Elpek, K. G., Tayalia, P., Collier, A. R., and Turley, S. J. (2011). Regulated release of nitric oxide by nonhematopoietic stroma controls expansion of the activated $\mathrm{T}$ cell pool in lymph nodes. Nat. Immunol. 12, 1096-1104.

Luther, S. A., Tang, H. L., Hyman, P. L., Farr, A. G., and Cyster, J. G. (2000). Coexpression of the chemokines ELC and SLC by T zone stromal cells and deletion of the ELC gene in the plt/plt mouse. Proc. Natl. Acad. Sci. U.S.A. 97, 12694-12699.

Luther, S. A., Ansel, K. M., and Cyster, J. G. (2003). Overlapping roles of CXCL13, interleukin 7 receptor $\alpha$, and CCR7 ligands in lymph node development. J. Exp. Med. 197, 1191-1198.

Mackay, C. R. (2001). Chemokines: immunology's high impact factors. Nat. Immunol. 2, 95-101.

Malhotra, D., Fletcher, A. L., Astarita, J., Lukacs-Kornek, V., Tayalia, P., Gonzalez, S. F., Elpek, K. G., Chang, S. K., Knoblich, K., Hemler, M. E., Brenner, M. B., Carroll, M. C., Mooney, D. J., Turley, S. J., and The Immunological Genome Project Consortium. (2012). Transcriptional profiling of stroma from inflamed and resting lymph nodes defines immunological hallmarks. Nat. Immunol. 13, 499-510.

Mebius, R. E., Rennert, P., and Weissman, I. L. (1997). Developing lymph nodes collect CD4+ CD3$\mathrm{LT} \beta+$ cells that can differentiate to APC, NK cells, and follicular cells but not T or B cells. Immunity 7, 493-504.

Mebius, R. E. (2003). Organogenesis of lymphoid tissues. Nat. Rev. Immunol. 3, 292-303.

Mueller, S. N., Hosiawa-Meagher, K. A., Konieczny, B. T., Sullivan, B.
M., Bachmann, M. F., Locksley, R. M., Ahmed, R., and Matloubian, M. (2007a). Regulation of homeostatic chemokine expression and cell trafficking during immune responses. Science 317, 670-674.

Mueller, S. N., Matloubian, M., Clemens, D. M., Sharpe, A. H., Freeman, G. J., Gangappa, S., Larsen, C. P., and Ahmed, R. (2007b). Viral targeting of fibroblastic reticular cells contributes to immunosuppression and persistence during chronic infection. Proc. Natl. Acad. Sci. U.S.A. 104, 15430-15435.

Mueller, S. N., and Germain, R. N. (2009). Stromal cell contributes to the homeostasis and functionality of the immune system. Nat. Rev. Immunol. 9, 618-629.

Müller, G., Höpken, U. E., and Lipp, M. (2003). The impact of CCR7 and CXCR5 on lymphoid organ development and systemic immunity. Immunol. Rev. 195, 117-135.

Nolte, M. A., Beliën, J. A., SchadeeEestermans, I., Jansen, W., Unger, W. W., van Rooijen, N., Kraal, G., and Mebius, R. E. (2003). A conduit system distributes chemokines and small blood-borne molecules through the splenic white pulp. J. Exp. Med. 198, 505-512.

Ohl, L., Henning, G., Krautwald, S., Lipp, M., Hardtke, S., Bernhardt, G., Pabst, O., and Förster, R. (2003). Cooperating mechanisms of CXCR5 and CCR7 in development and organization of secondary lymphoid organs. J. Exp. Med. 197, 1199-1204.

Palframan, R. T., Jung, S., Cheng, G., Weninger, W., Luo, Y., Dorf, M., Littman, D. R., Rollins, B. J., Zweerink, H., Rot, A., and von Andrian, U. H. (2001). Inflammatory chemokine transport and presentation in HEV: a remote control mechanism for monocyte recruitment to lymph nodes in inflamed tissues. J. Exp. Med. 194, 1361-1373.

Phan, T. G., Green, J. A., Gray, E. E., Xu, Y., and Cyster, J. G. (2009). Immune complex relay by subcapsular sinus macrophages and noncognate B cells drives antibody affinity maturation. Nat. Immunol. 10, 786-793.

Roozendaal, R., Mempel, T. R., Pitcher, L. A., Gonzalez, S. F., Verschoor, A., Mebius, R. E., von Andrian, U. H., and Carroll, M. C. (2009). Conduits mediate transport of low-molecular-weight antigen to lymph node follicles. Immunity 30 , 264-276.
Roozendaal, R., and Mebius, R. E. (2011). Stromal cell-immune cell interactions. Annu. Rev. Immunol. 29, 23-43.

Scandella, E., Bolinger, B., Lattmann, E., Miller, S., Favre, S., Littman, D. R., Finke, D., Luther, S. A., Junt, T., and Ludewig, B. (2008). Restoration of lymphoid organ integrity through the interaction of lymphoid tissue-inducer cells with stroma of the $\mathrm{T}$ cell zone. Nat. Immunol. 9, 667-675.

Sixt, M., Kanazawa, N., Selg, M., Samson, T., Roos, G., Reinhardt, D. P., Pabst, R., Lutz, M. B., and Sorokin, L. (2005). The conduit system transports soluble antigens from the afferent lymph to resident dendritic cells in the $\mathrm{T}$ cell area of the lymph node. Immunity 22, 19-29.

Steinman, R. M., Pack, M., and Inaba, K. (1997). Dendritic cells in the T-cell areas of lymphoid organs. Immunol. Rev. 156, 25-37.

St John, A. L., and Abraham, S. N. (2009). Salmonella disrupts lymph node architecture by TLR4mediated suppression of homeostatic chemokines. Nat. Med. 15, 1259 1265.

Suzuki, K., Maruya, M., Kawamoto, S., Sitnik, K., Kitamura, H., Agace, W. W., and Fagarasan, S. (2010). The sensing of environmental stimuli by follicular dendritic cells promotes immunoglobulin A generation in the gut. Immunity 33, 71-83.

Szabo, M. C., Butcher, E. C., and McEvoy, L. M. (1997). Specialization of mucosal follicular dendritic cells revealed by mucosal addressincell adhesion molecule-1 display. $J$. Immunol. 158, 5584-5588.

Szakal, A. K., Holmes, K. L., and Tew, J. G. (1983). Transport of immune complexes from the subcapsular sinus to lymph node follicles on the surface of nonphagocytic cells, including cells with dendritic morphology. J. Immunol. 131, 1714-1727. Taylor, P. R., Martinez-Pomares, L., Stacey, M., Lin, H. H., Brown, G. D., and Gordon, S. (2005). Macrophage receptors and immune recognition. Annu. Rev. Immunol. 23, 901-944.

Tew, J. G., Wu, J., Qin, D., Helm, S., Burton, G. F., and Szakal, A. K. (1997). Follicular dendritic cells and presentation of antigen and costimulatory signals to B cells. Immunol. Rev. 156, 39-52.

Tomei, A. A., Siegert, S., Britschgi, M. R., Luther, S. A., and Swartz, M. A.
(2009). Fluid flow regulates stromal cell organization and CCL21 expression in a tissue-engineered lymph node microenvironment. J. Immunol. 183, 4273-4283.

van de Pavert, S. A., Olivier, B. J., Goverse, G., Vondenhoff, M. F., Greuter, M., Beke, P., Kusser, K., Höpken, U. E., Lipp, M., Niederreither, K., Blomhoff, R., Sitnik, K., Agace, W. W., Randall, T. D., de Jonge, W. J., and Mebius, R. E. (2009). Chemokine CXCL13 is essential for lymph node initiation and is induced by retinoic acid and neuronal stimulation. Nat. Immunol. 10, 1193-1199.

Veiga-Fernandes, H., Coles, M. C., Foster, K. E., Patel, A., Williams, A., Natarajan, D., Barlow, A., Pachnis, V., and Kioussis, D. (2007). Tyrosine kinase receptor RET is a key regulator of Peyer's patch organogenesis. Nature 446, 547-551.

Victoratos, P., Lagnel, J., Tzima, S. Alimzhanov, M. B., Rajewsky, K., Pasparakis, M., and Kollias, G. (2006). FDC-specific functions of p55TNFR and IKK2 in the development of FDC networks and of antibody responses. Immunity 24, 65-77.

Zindl, C. L., Kim, T. H., Zeng, M., Archambault, A. S., Grayson, M. H., Choi, K., Schreiber, R. D., and Chaplin, D. D. (2009). The lymphotoxin LT $\alpha 1 \beta 2$ controls postnatal and adult spleen marginal sinus vascular structure and function. Immunity 30 , 408-420.

Conflict of Interest Statement: The author declares that the research was conducted in the absence of any commercial or financial relationships that could be construed as a potential conflict of interest.

Received: 01 June 2012; accepted: 28 June 2012; published online: 12 July 2012

Citation: Katakai T (2012) Marginal reticular cells: a stromal subset directly descended from the lymphoid tissue organizer. Front. Immun. 3:200. doi: 10.3389/ fimmu.2012.00200

This article was submitted to Frontiers in Antigen Presenting Cell Biology, a specialty of Frontiers in Immunology. Copyright (C) 2012 Katakai. This is an open-access article distributed under the terms of the Creative Commons Attribution Non Commercial License, which permits non-commercial use, distribution, and reproduction in other forums, provided the original authors and source are credited. 